\title{
The Basis of Equality
}

\author{
GEOFFREY CUPIT
}

\section{The Issue}

It is often said that justice requires equality. Which kind of equality justice requires is, of course, a matter of dispute: it is widely held that in a just society there must be equality before the law, and equality of opportunity; many have claimed that justice requires equality of concern for the welfare of each person; and some have argued that significant inequalities in the allocation of resources must be avoided. And, of course, many believe that justice requires public affairs to be conducted through democratic institutions-for only such arrangements express an equality of political status, and seek to provide an equality of influence.

If we ask why justice should be thought to require such equalities, we are likely to be given one (or both) of the following responses-one positive, the other negative. According to the positive response there is a general requirement to treat people as equals; and treating people as equals requires at least certain kinds of equality or equal treatment. ${ }^{1}$ The positive response, then, appeals to a general claim: people are to be treated as equals. The negative response is content merely to challenge particular assertions of superiority-usually the assertions of superiority based on the traditional considerations of birth, race, sex, and so on. Such claims to superior status cannot be made out-so the negative argument goes-and thus it is unjust to treat people as superior or inferior on the basis of such considerations. And where there are no relevant grounds to discriminate-the argument continues-equal treatment is required.

I want to focus in this paper on the positive response. There may be nothing wrong with the negative response as far as it goes. But it seems that something will be lost if the positive response cannot be sustained. ${ }^{2}$ I want, then, to examine whether there is any general

${ }^{1} \mathrm{Cf}$. '... the right to treatment as an equal is fundamental, and the right to equal treatment, derivative' (Ronald Dworkin, Taking Rights Seriously (London: Duckworth, 1977) p. 227).

${ }^{2}$ The negative response seems, by virtue of its negative and particular character, a weaker basis on which to try to defend (any particular) equality or equal treatment. First, to the extent that the response merely challenges arguments grounding (particular) bases of inequality, it leaves open 


\section{Geoffrey Cupit}

requirement of justice to treat people as equals. ${ }^{3} \mathrm{I}$ examine two approaches. The first attempts to derive the requirement to treat as an equal from the claim that we are equal. I argue that this approach offers little prospect of success. The second strategy is to try to derive the requirement to treat as an equal, not from any equality, but from the claim that we are individuals. I shall suggest that a

${ }^{3} \mathrm{I}$ focus on this question, and leave aside the question of how, if it is indeed necessary to treat people as equals, this is to be done. The question of how people are to be treated as equal raises a number of issues, one of

the possibility that even those bases may be satisfactorily grounded on other arguments. Second, in so far as the argument attacks only particular bases of inequality, it fails to show that other bases for unequal treatment do not remain. (A piecemeal approach to defending equality is always liable, in the end, to do no more than justify the replacement of one form of inegalitarianism with another-to remove some bases of inequality only to leave the field free for the fuller acknowledgment of others.) Third, the negative response relies on the claim that where we have no relevant grounds to discriminate, equality and equal treatment are requirements of justice. Capricious unequal treatment is, on this view, by its very nature,

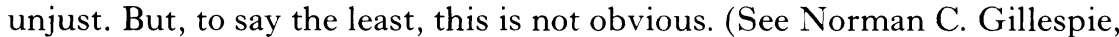
'On Treating Like Cases Alike', Philosophical Quarterly 25 (1975) pp. 151-8.) Why should we suppose that there exists the simple, conceptual relationship between equality and justice which is required to make this so? Why should we not say that any injustice in unequal treatment stands in the same need of explanation as does injustice in treatment in general? Fourth, in general we might expect the negative response to require only that we avoid treating people in ways that would express (particular) inequalities. (We need to include 'in general' here for in some contexts mere avoidance may not be enough. In some contexts 'silence' may express.) By contrast, if we are positively required to treat people as equals then mere avoidance of treating as unequal (together even with the positive expressions required by context) may not be enough. Thus the negative response may be weak in this further way: a set of practices may avoid treating people as unequal (in whatever ways they are not unequal) yet fall short of treating people as equals. Thus equalities and equal treatments that may be required if it is necessary to treat people as equals, may not be required if it is enough that we avoid treating people as unequals. Given the weakness of the negative response, then, it seems that something important is lost if the positive response cannot be sustained. By accepting this we will be able to explain why '[a]lthough most movements for equality can be interpreted in terms of protests against specific inequalities, a strong disposition nevertheless exists, among philosophers and others, to argue that whatever men's actual differences and whatever their genuine relevance for certain kinds of differentiation, there yet remain important values in respect of which all men's claims are equal' (Stanley I. Benn, 'Egalitarianism and the Equal Consideration of Interests' reprinted in Hugo A. Bedau (ed.), Fustice and Equality (Englewood Cliffs, N. J.: Prentice-Hall, 1971) p. 156. 
derivation of this kind is more promising. If successful, then, this paper will give some support to the view that the proper foundation of egalitarianism is individualism.

Before turning to the arguments I want to make three prefatory points. The first concerns how 'equal' is to be understood in the expression 'treating as equal'. I shall take equal in this context to mean 'being on the same status level', that is, being neither superior nor inferior. To say that people are to be treated as equals, then, is to say that people are to be treated as holding the same rank in at least one hierarchy. (It is also to imply that such talk makes sensethat it is coherent. We cannot talk of people being equal in status and then deny that such talk makes sense.)

Second, I want to emphasize that I shall be concerned throughout only with the question of whether people ought, as a matter of justice, to be treated as equals. Thus I set aside what might be termed pragmatic reasons. Treating all as equal may be conducive to peace and social harmony, giving us the best chance to rub along with each other. ${ }^{4}$ It may provide us with the greatest pool from which to draw our friends and lovers-if such relationships presuppose a certain equality of status. ${ }^{5}$ These may be reasons of a kind to treat people as equals; but such prudential considerations provide no reason to think that treating people as equals is required as a matter of justice. Or so, at least, I shall assume.

My final introductory point concerns my use of 'egalitarian'. I want to consider whether justice requires people be treated as equals, and I shall refer to the view that they ought as 'the

${ }^{4}$ For a discussion of some of the social factors which may promote egalitarianism see Ernest Gellner, 'The Social Roots of Egalitarianism', reprinted in Culture, Identity, and Politics (Cambridge University Press, 1987).

${ }^{5}$ As has been suggested: 'Although almost every human need can be met by superiors and inferiors, the companionship which is the answer to loneliness can come only from equals' (Henry Alonzo Myers, Are Men Equal? (Ithaca, N.Y.: Cornell University Press, 1955) p. 31).

which is: how far is equal treatment required in order to treat as an equal? In many contexts, preferential treatment seems (to many) not to constitute treating as superior-and thus not to constitute a failure to treat as an equal. Many of the preferential treatments we give to our friends and relatives (such as naming them in our wills) carry no implication of superiority. Even in contexts where impartial judgment might seem particularly appropriate, it is not clear that unequal treatment is always to be condemned as a failure to treat as an equal: if all are equally deserving of punishment, and some are allowed to go unpunished (by an act of mercy or amnesty), it is not clear that such unequal treatment constitutes a failure to treat all as equals. 


\section{Geoffrey Cupit}

egalitarian position'. Now I do think that such a view is properly considered to be at the heart of egalitarianism. I take egalitarianism to be a doctrine about equality and justice; and I take justice to be a virtue that requires we treat appropriately. ${ }^{6}$ But in using 'egalitarian' here I do not mean to presuppose these claims. My interest in this paper is not in the nature of egalitarianism, but in whether justice requires people be treated as equals. I use 'egalitarian' only as a convenient label for a particular response to this question.

\section{The Argument from our Equality}

Why should justice require that people be treated as equals? The simplest argument for this claim is: people ought to be treated as equals because they are equals. Such an argument has its strengths. It seems plausible to say that if people are equals, they ought, at least sometimes, to be treated as such. The problem with the argument is with its premise. Why should we accept that people are equals? To be sure, this claim seems widely endorsed. Yet it is very far from being self-evident. Indeed, on the face of it, the claim seems highly implausible. People differ enormously. Some are kind, thoughtful and tolerant, contributing significantly to the common good; others are really quite despicable-malicious, bigoted and self-centred, they make no attempt to improve themselves, or to return to society any of what they take. Given the many differences between people-and their spread along a continuum from the wholly admirable to the perfectly contemptible-why should we suppose that there is any sense in which they are all equal?

To be sure we should not exaggerate our differences, and the egalitarian may well wish to remind us of our similarities. We all feel pain, experience suffering; we all plan our lives, hope, and suffer disappointments; we all reason, make choices, exercise our free wills, and are responsible. It may well be that we have much in common, that what distinguishes us from other beings and entities is more significant than the differences between us, and that we really are all very much the same sort of being. ${ }^{7}$ But it hardly follows from this that we are equal. Our all being human, even if it makes us similar, does not make us equal. All carrots are carrots, and all books are books: but that is no reason to suppose that there is, therefore, a

${ }^{6}$ For a defence of the claim that justice is to be understood as, at root, exclusively concerned with appropriate treatment of this kind see my Fustice as Fittingness (Oxford University Press, 1996), especially Chapter 1 .

' Cf. Bernard Williams, 'The Idea of Equality', reprinted in Hugo A. Bedau (ed.), Fustice and Equality, especially pp. 118-9. 


\section{The Basis of Equality}

significant sense in which all carrots are equal, or all books are equal. Similarity is not to be equated with equality. An argument for equality is thus required.

The natural way to argue for our equality, it seems, is to argue that there is something in which we are all equal-that there is some feature or attribute which we all have to the same degree. ${ }^{8}$ Not any attribute will do. First, we must be willing to regard the feature or attribute as status-affecting-as relevant to an appraisal of us-if we are to be able to offer it as a basis for our equality. Second, we must be willing to claim that the attribute affects our status in some unusually significant way-if it is to ground the claim that there is a fundamental sense in which we are all equal.

But now the difficulty in arguing for our equality is manifest. Given that there are billions of people, it seems reasonable to expect variation in all attributes, absurd to suppose that there is anything with which we are all equally endowed. ${ }^{9}$ It seems, then, that we cannot expect to base our equality on anything that might vary from one person to another. And thus we may be tempted to try to found it instead on attributes that cannot possibly vary. We might be tempted to say that we are all equally human, ${ }^{10}$ or all equally unique individuals, and thus equals.

But such an argument tries to have its cake and eat it. To claim that we are equally human (say) is to claim that we are human to the same extent or degree, and thus to imply that it makes sense to talk of degrees of humanity; while, in so far as no evidence or argument for our alleged equal humanity is offered or thought necessary, the assumption is that it makes no sense to talk of degrees of humanity. But we cannot have it both ways. ${ }^{11}$

${ }^{8}$ An alternative is to argue that our equality derives not from withinfrom what is (in some sense) intrinsic to us-but is imposed, or at least derives, from without. It might be said, for example, that we are equals because God makes it so. (For a discussion of the relationship between egalitarianism and theism see Louis P. Pojman, 'A Critique of Contemporary Egalitarianism: A Christian Perspective' in Faith and Philosophy 8 (1991) pp. 481-504.)

${ }^{9}$ And, of course, even if an attribute did not vary, the mere fact that it could would be sufficient to make the claim that we are equals into a (highly) contingent one.

${ }^{10}$ An argument for our equality from our common humanity may, of course, be precluded by the requirement that our equality be based on an attribute we are willing to regard as status-affecting. We cannot base our equality on our humanity per se, unless we are willing to claim that species membership is, in itself, status-affecting.

${ }^{11}$ It may also be objected that in such an argument equality does no work. 'To say that all men, because they are men, are equally men, or that 


\section{Geoffrey Cupit}

What other moves can the egalitarian make? One is to try to found equal status on passing some threshold, or on possession of some 'range property'. ${ }^{12}$ We may not all be equal in rationality or intelligence, in our exercise of autonomy, or whatever; but we all (or most of us, at least) pass some threshold, fall within some range, and on that basis, so the argument goes, are properly to be regarded as equals. But such an argument seems wholly ad hoc. From where does any threshold get its force? Why should we suppose that our status is determined by our passing a particular threshold, whilst our possessing more than the minimum required to pass that threshold is entirely redundant? And why should we suppose that passing a threshold has the kind of fundamental significance associated with our supposed equality?

Another move is to argue, not from any equal actuality, but from our equal potentiality. Here it is claimed that we all have the same potential-or, at least, the same potential in some significant area, such as our capacity for acting virtuously. But such an argument faces two areas of difficulty.

First, we might wonder whether it is reasonable to suppose that our fundamental status is determined by our potential (even in some significant field). Our potential may never be realized. Can an unrealized potential-say, the capacity to do good we will never actually do, or the capacity to realize virtues and qualities we will never actually realize-really determine our status in a fundamental sense? Or is this to give too much consideration to what we might (in some sense) have been, rather than to what we actually are?

Second, even if it is true that a fundamental assessment of us ought to be based on our potential, the egalitarian will still need to show that we do all have the same potential (in some significant field, at least) - and presumably in a manner which leaves us with a

${ }^{12}$ For an argument appealing to the idea of a range property see John Rawls, $A$ Theory of Justice (Oxford University Press, 1972), p. 508.

to treat any two persons as ends in themselves is to treat them as equally ends in themselves is to import a spurious note of egalitarianism into a perfectly sound and serious argument. We may call it, if we like, the argument from Equality of Respect, but in this phrase it is the word "Respect"-respect for each man's humanity, respect for him as a human being-which is doing the logical work, while the word "Equality" adds nothing to the argument and is altogether otios $\rightarrow(J$. R. Lucas, "Against Equality' Philosophy 60 (1965), p. 298). But perhaps this is too harsh. It might be argued that to say that we are all equally human is to say something more than that we are all human: it might be argued that it attempts, at least, to give expression to a comparison between us in terms of our humanity. 


\section{The Basis of Equality}

tolerably concrete identity. It is hardly possible to believe that we have the same intellectual potential. But is it any more plausible to suppose that we all have the same potential for virtue? It may seem profoundly unfair that, say, our capacity for virtue depends on external factors, and not entirely 'on us'. But from its being unfair, it hardly follows that it is not so. On the face of it, cats lack the capacity most humans have for virtue-and presumably through no fault of their own. Why should we not accept that the kind of variations in potentialities which we think exist between species, also exist within (the human) species-albeit, no doubt, to a lesser degree? At the very least, our having an equal potential for virtue seems a good deal less evident than our fundamental equality is supposed to be.

As we noted, mere similarity seems insufficient to ground a claim of equality. What the egalitarian requires, it may seem, is to go beyond an assertion of similarity to an assertion of identity. And since our differences are so apparent, the argument must be that those differences are indeed only apparent. Superficially we may appear different, but, so the argument must go, underneath we have real selves which are all the same. This is the argument for equality from a thin and uniform conception of the self. On such an account many of our attributes are stripped from the self, to be viewed as at most associated with, rather than constitutive of, the self. By stripping away our various attributes we get down to our inner core, our real selves, our essential being-and that core, so the argument goes, is the same for all. ${ }^{13}$ Our fundamental equality, then, is underpinned by our identical identities.

But there are (at least) two problems with such an argument: the conception of the self it assumes; and the kind of egalitarianism it implies. The problems with the conception of the self come in a number of forms. First, the thin conception of the self seems barely coherent. Does the account leave us with anyone to be? Is there

${ }^{13}$ This process of stripping the self may be thought of as the progressive removal of layers. Perhaps our social roles are the outermost layer. Removing this layer requires that I come to see myself as taking on the roles of farmer or teacher, say, rather than being, in my true self, a farmer or teacher. (Cf. Alasdair MacIntyre, After Virtue (London: Duckworth, 1981) p. 32.) My physical attributes represent another level. My body is not to be confused with the real me (so the argument may go), and thus its physical attributes need not be viewed as constitutive of me. Finally (perhaps) we come to aspects of character such as my generosity or courage. These may be seen as having their origins in what has merely happened to me, in my coming to have certain genes, or through the nurturing, educative, and socialising experiences I have undergone. As such we might view them as mere attributes which stand always at a certain distance from me. 


\section{Geoffrey Cupit}

anything left after all that is contingent has been stripped away? Second, we generally suppose that at least some of our dignity derives from our unique character; but if we are really all the same, that dignity and individuality seems threatened. Third, the account seems inconsistent with our self-image. We usually suppose that we are able to discover things, and to change things, about our particular selves. But we can make discoveries about our individual natures only if we have individual natures to discover; we can degrade or ennoble ourselves only if our selves are capable of change. For a number of reasons, then, the idea that underneath appearances we are identical seems unattractive. We have an inclination to view our differences as going through to our core. We may be mistaken to take this view-but it is not clear that we are. One problem with the argument from identity, then, is that it tries to base our equality on what is, at best, a highly controversial conception of the self. As such it fails to provide that assertion of equality with a sufficiently solid foundation.

Nor, it seems-to anticipate a point I shall make more of in a moment-is the egalitarianism that flows from such an account of an acceptable kind. Any claim that we are equals worth taking seriously must be consistent with the fact that there are significant respects in which some people are superior to-more admirable, more worthy, than-others. It would be absurd to deny that, for example, Mandela is the superior of Hitler. We are not to suppose that the assertion of our equality exhausts all there is to say about our relative status or merits. Even if we are equals, we are also unequals. But if that is so, then the argument from identity seems in danger of proving too much. If the differences between us are mere appearances, then it is hard to see what reason we can have to think of some as genuinely superior to others. Thus to assert that our real selves are unchanging and identical is to risk producing an argument for an absurd kind of egalitarianism.

It is, then, hard to see on what our alleged equality can be based: it is hard to find anything (of a suitable kind) in which we are all equal. But even if this problem can be solved, and some suitable equality identified, the egalitarian will only have reached first base. It will still need to be explained why any particular equality is not overwhelmed by our inequalities. The problem is this. If we are equal in some things, unequal in others, it seems to follow that all things considered we are unequal. But if this is so, how can we claim to be fundamentally equal? Why, after all, shouldn't any fundamental assessment of us be made on an 'all things considered' basis? But if it is made on that basis, how can we avoid concluding that we are unequal? 
There are, in principle, three ways in which the egalitarian might attempt to deal with this problem. First, it might be argued that there are no attributes relevant to our fundamental status in which we are unequal. Given the manifest differences between us, and the apparent relevance of some of those differences to (some) assessments of us, this may seem a tall order. Perhaps the least implausible way to defend this position is to argue that there is a level of assessment of us that is unaffected by our inequalities. The attributes in which we are equal go deeper than those in which we are unequal. Hence a genuinely fundamental assessment of us can find us equals. ${ }^{14}$ But such a view is surely unacceptable. Why should we suppose that there is a level of appraisal immune to saintliness or depravity, a level our virtue or evil cannot reach? Why should we deny that our merit or demerit goes right through to our core? Such a view would imply that the evaluation-affecting differences between Hitler and Mandela go only so far down; that the most profound assessment of them finds them equals. But that seems an absurd thesis-and much too high a price to pay to defend the egalitarian position.

A second strategy is to accept that we have inequalities, but claim that they exactly cancel out to equality. But this is even less plausible than the first strategy: if we are equal, our equality is not, surely, the result of such a stupendously unlikely coincidence. There is simply no reason to suppose that all people are all things considered equals. Indeed, quite the reverse.

The third strategy - and the only one worthy of serious consideration-appeals to the idea of a multiplicity of fundamental assessments. ${ }^{15}$ On this view there are a plurality of possible fundamental

${ }^{14}$ We can take this line without endorsing the view that our real selves are identical. We may hold that there are differences between our real selves but that those differences do not affect our status or worth.

${ }^{15}$ I take it that this is the move typically made by egalitarians at this point-and that it (normally, at least) takes the form (in part) of invoking a distinction between assessments made on the basis of what we 'are' and what we 'do'. We are manifestly unequal in terms of our actions. The egalitarian's claim can only be, then, that we are, nevertheless, in the same sort or class of beings, and have the same status in virtue of the kind of beings we are. There is no doubt that we $d o$ often distinguish between what we are and what we do, and that we offer assessments which purport to be based exclusively either on our natures, or on our actions (and omissions). And the distinction is well marked in our language. The focus seems to be exclusively on what a person has done when we make (what we call) a 'moral' assessment or ranking, and when we allot punishment and reward. (It is-or so it seems-appropriate to punish and reward only for what people do, not for what they are.) And some have suggested that 'desert' is 


\section{Geoffrey Cupit}

assessments of us, and at least one of these assessments is based exclusively on attributes in which we are equal. On this view, then, on at least one assessment we are fundamentally equal for, when making that assessment, our inequalities are left aside. ${ }^{16}$

The problem with this view is to explain how an assessment can be both fundamental in character and restricted to certain parameters. How can we justify the claim that there is a fundamental assessment of us which does not take everything into account? To be sure we often do make assessments in terms of some particular parameter, or some particular set of parameters, and simply leave aside other considerations. This is because we often assess for a

${ }^{16}$ If such a view can be defended then much - if not all-of the sting can be drawn from the charge that: 'Since egalitarians are committed to such absurd consequences of their position as, for instance, that Stalin or Hitler and Einstein or Hume have equal human worth, they should give up their position' (John Kekes, 'Human Worth and Moral Merit', Public Affairs Quarterly 2 (1988) p. 67). If the egalitarian were committed to such assessments as the sole fundamental assessment to be made, the egalitarian's position would indeed be absurd. But it is not absurd (at least to those sympathetic to egalitarianism) to make such an assessment if it is to be understood in such a way as not to preclude other (fundamental) assessments according to which those compared are unequal. Of course it remains to defend the practice of making multiple fundamental assessments.

appropriately used only when the putative basis of desert is an action, and that 'merit' is to be used in cases where the basis is something for which we are not responsible. (See, for example, J. R. Lucas, Responsibility (Oxford: Clarendon Press, 1993) pp. 124-7.) This is not to say, however, that the distinction is a clear one. In understanding and assessing what we are we view ourselves as unchanging-or very largely so. But why should we suppose that what we are remains untouched by the actions we perform? Is it not reasonable to say that people who live in a particular way are loving or selfish, or just or unjust - that what we do does change who or what we are? Is it not a mistake to suppose that (at least many of) our actions always stand at a certain distance from us, are never more than merely associated with us? The extreme view that we cannot change what we are no matter how awfully we act is often rejected: acts of a certain gravity are often supposed to put those who perform them beyond a certain pale; those who have acted in such ways really are different from the rest of us. But if this is so, why is it a mistake to think of more common acts as affecting who we are? Why is it a mistake to suppose that who or what we are is, in part, constituted by what we have done or not done? Again it is not that the use of the distinction between what we are and what we do is unreasonable-indeed it is hard to see how we could get by without it. Rather the point is that here again the argument for treating as an equal from our supposed equality seems to rely on a claim which may be thought weaker than the requirement to treat as an equal is supposed to be. 
particular purpose. When we need a good musician or scribe we assess people as musicians or as writers, and we rightly leave aside many attributes as irrelevant. But such assessments are hardly fundamental. It seems that when we assess people for a particular purpose our assessment is not fundamental; and when we make a fundamental assessment we are not assessing people for any particular use. (And, of course, if we did assess all people for any particular purpose, we should not expect to find them equal.)

Nor can a partial assessment of us as equals be defended by simple appeal to a multiple aspect view, or by merely claiming that there is a perspective from which our inequalities do not count. Talk of aspects or perspectives, if taken seriously, invokes the notion of subjectivity-or of quasi-subjectivity, at least. But the introduction of subjectivity here undercuts the objectivity of the conclusion. Why should merely looking equal, when viewed from a particular point of view, entail that justice requires we be treated as equals? Justice requires that we treat as saints those who are saints (and perhaps those who we have good reason to think are saints); but it does not require that we treat as saints those who merely exhibit an appearance of saintliness.

We need, then, an explanation of how the assessment that we are all equal can be both partial and fundamental. It might be thought that the incommensurability of different (sets of) attributes can serve to justify partial yet fundamental assessments. Suppose there is some attribute (or set of attributes) $\mathrm{X}$, in which we are equal, and that $\mathrm{X}$ is incommensurable with our other attributes. There is, therefore, let us suppose, no rational way to compare or combine $\mathrm{X}$ with our other attributes. It may seem to follow that separate and distinct assessments must therefore be made. To be sure, it may be admitted, not all assessment and evaluation need be algorithmic. There is room for a more 'humanistic' kind of judgment. But, so the argument might run, there still needs to be some basis on which different considerations are to be combined; and it might be argued that such a basis is lacking in this case.

But there is an objection to such an argument from incommensurability-when it is offered in a defence of the egalitarian position. The argument relies on the existence of a problem which, if the premises of the argument are true, does not exist. Suppose, for the sake of argument, we accept the existence of $\mathrm{X}$-an attribute (or set of attributes) in which we are equal, and which is incommensurable with our other attributes. It does not follow that we can not produce a ranking which takes account of both $\mathrm{X}$ and our other attributesfor a ranking based on those other attributes alone is tantamount to a 'combined' assessment. Ex hypothesi, there are no differences in $\mathrm{X}$ to 


\section{Geoffrey Cupit}

affect the ranking. It seems, then, that mere incommensurability is unable to explain why we should suppose there to be a partial assessment of us according to which we are fundamentally equal. There remains, then, a problem for the egalitarian: even if there is something in which we are equal it still needs to be explained why it follows that we are fundamentally equal-why any equality is not overwhelmed by our inequalities in any fundamental assessment of us.

\section{The Argument from our Individuality}

We have sought, unsuccessfully, a basis for our supposed equality. There may, of course, be a satisfactory argument for our equality that I have overlooked. But it is not encouraging to note that even committed egalitarians admit to knowing of no satisfactory argument for our equality. ${ }^{17}$ Suppose we start to doubt that there is any plausible argument for the claim that we are fundamentally equal. Should we also start to doubt that justice requires people be treated as equals? Or can the egalitarian position be defended without appeal to the idea that we are all equal? In this section I want to consider whether this is possible, and whether justice might require that people be treated as equals, not because they are equals, but because they are individuals.

The suggestion that there is a link between individualism and egalitarianism - and that individualism may underpin egalitarianism-is hardly novel. ${ }^{18}$ There is a long tradition of combining the values of individualism with equality. One of the doctrines associated with individualism is the natural sovereignty of each person. We are not born masters and servants, rulers and ruled. All are born free; no one may claim natural authority over another. The absence

17 'I don't know any way of arguing for [the equal fundamental worth of all human beings] ...' (John Baker, Arguing for Equality (London: Verso, 1987) p. 71).

${ }^{18}$ Lukes, for example, has claimed that 'the principle of respect for persons, as "ends in themselves", in virtue of their inherent dignity as individuals, is at the basis of the ideal of human equality' (Steven Lukes, Individualism (Oxford: Basil Blackwell, 1973) p. 125). However Lukes seems to rest this claim on the argument from what we have in common: 'respect is equally due to all persons-in virtue of their being persons, that is of some characteristic or set of characteristics which they have in common-and since, as I shall argue, respecting them requires doing all one can to maintain and increase their freedom (and to discriminate between them in this regard is to fail to show them equal respect)' (ibid, pp. 125-6). But, as we noted earlier, such an argument seems vulnerable to the objection that there are significant differences between us. 
of any natural hierarchy of authority places us all on the same level-makes us equals-in the state of nature at least. Descriptions of the state of nature have typically been descriptions of individual sovereignty, and of equality-as far as authority is concerned. ${ }^{19}$

But such equality is distinct from the claim that we are equal in fundamental worth; there is no argument yet for our deserving to be treated as fundamentally equal. But nor, as yet, is there any argument for the claim that individuals are indeed sovereign. And the possibility arises, therefore, that in answering the question of what makes an individual sovereign, we may provide a basis on which to argue for our being treated as beings of equal fundamental worth. My suggestion, then, is that if we look at what lies behind the claim to the sovereignty of the individual (in the state of nature) we may find a ground on which to argue for an equality of wider import.

Why should we suppose that no individual has a natural right to command another? What precludes the more able, say, having a duty, and a right, to interfere with, and to direct, the less able? To be sure, there are the consequentialist arguments against such interference that we associate with Mill. Non-interference, in general at least, seems likely (given a certain level of development) to lead to the improvement of the individual; and given that individuals have the greatest knowledge of their own particular circumstances and interests, interference for paternalistic reasons is likely to be counterproductive. But what explains why such interference is in itself unjust, and irrespective of the consequences?

One argument for the injustice of such interference is that it is only by acknowledging the sovereignty of each individual that we respect each person as a separate and independent being. ${ }^{20}$ Claiming

${ }^{19}$ For example, Locke, in the opening paragraph of Chapter II of the Second Treatise, highlights individual independence and equality as features of the state of nature. Locke's argument there is that the state of nature is a state of equality since there is 'nothing more evident, than that creatures of the same species and rank promiscuously born to all the same advantages of nature, and the use of the same faculties, should also be equal' unless God directs otherwise. Unfortunately Locke's claim that we are of the same rank seems to beg the question, while his claim that we are of the same species and have the use of the same faculties simply fails to address the problem raised by the fact that there are differences between us. More recently, Rawls' account of the original position combined independence and equality: Rawls set out to determine the principles which would be chosen by 'rational and independent persons in an original position of equality', claiming that, by acting on those principles people would 'express their nature as free and equal rational beings' (John Rawls, $A$ Theory of Fustice, p. 252).

${ }^{20}$ An alternative argument is that non-interference is required in order 


\section{Geoffrey Cupit}

a right to direct others-even in their own interests-fails to keep the distance between people which is required in order properly to reflect the separation which exists (or is thought to exist) between people. And justice-for reasons which, of course, will need to be explained-requires the acknowledgment of that separation. The doctrine of individual sovereignty derives, on this account, from a particular (metaphysical) understanding of who or what we are, and how we stand in relation to each other.

The conception of each person as a (radically) separate being is often termed 'atomism'. But the metaphor of atoms seems inappropriate: individualism is a doctrine which emphasizes the dignity and worth of each individual; it is scarcely in keeping with such an account to compare each individual with a mere atom! A more appropriate image is suggested in the following passage:

It was about forty yards to the gallows. I watched the bare brown back of the prisoner marching in front of me. He walked clumsily with his bound arms, but quite steadily, with that bobbing gait of the Indian who never straightens his knees. At each step his muscles slid neatly into place, the lock of hair on his scalp danced up and down, his feet printed themselves on the wet gravel. And once, in spite of the men who gripped him by each shoulder, he stepped slightly aside to avoid a puddle on the path.

It is curious, but till that moment I had never realized what it means to destroy a healthy, conscious man. When I saw the prisoner step aside to avoid the puddle I saw the mystery, the unspeakable wrongness, of cutting a life short when it is in full tide. This man was not dying, he was alive just as we are alive. All the organs of his body were working-bowels digesting food, skin renewing itself, nails growing, tissues forming-all toiling away in solemn foolery. His nails would still be growing when he stood on the drop, when he was falling through the air with a tenth-of-asecond to live. His eyes saw the yellow gravel and the grey walls,

to treat people as the free, autonomous beings they are. But it is not clear that such an argument would be sound. Why should we suppose that to constrain a person is to treat that person as unfree? (It may treat the person as unworthy of freedom-but that is a different point, and one which raises the issue of why a person should be thought worthy of freedom. At that point the appeal to separation may appear.) But even if non-interference is generally required in order to treat people as free and autonomous beings, it seems doubtful that interfering to constrain actions which will significantly limit the actor's future freedom is inconsistent with a requirement to treat as free. At best this argument seems able to provide only a very circumscribed argument for the injustice of coercion. 


\section{The Basis of Equality}

and his brain still remembered, foresaw, reasoned-even about puddles. He and we were a party of men walking together, seeing, hearing, feeling, understanding the same world; and in two minutes, with a sudden snap, one of us would be gone-one mind less, one world less. ${ }^{21}$

Orwell captures here some of the central strands of an individualist understanding of our condition. To be sure we 'walk together'-but we are distinct and separate. We come into, and go out of, existence discreetly. Our bodies are distinct, and above all we have distinct and separate consciousnesses: 'one mind less, one world less'.

How would conceiving of each person as a separate world enable us to explain why justice requires that each person is to be treated as having an equal fundamental worth? What is the connection between being treated as an individual, and being treated as an equal? To answer this question, consider how people are to be treated if they are indeed separate worlds, and if justice requires that they be treated as such. How is our separation to be expressed? In particular, how is an acceptance that people are radically separate to find expression when they are assessed or ranked? A first requirement, it seems, is that people must not be assessed exclusively in terms of their contribution to ends which are not their own, or exclusively in terms of their place in some greater scheme of things. We are not to be ranked simply on the basis of the roles we play, or as the means or tools to the achievement of others' ends.

But further, we might argue that treating individuals as separate worlds requires that we qualify the comparative assessments we make of different individuals, or, at least, that we mark a proper hesitation in making such assessments. This is because there is, we might argue, a tension between treating people as separate worlds, and making comparisons between them. In making an assessment of someone by comparing that person with others we, as it were, go outside or beyond that particular individual. We give expression to this idea when we say (rather impractically) that each individual is of infinite worth. In some ways this is a puzzling claim-but it seems clear that it is intended to express the idea that individuals cannot be valued by going outside the world each is, and to give expression to their incomparability.

The inclination to say that individuals are of incomparable worth seems widely experienced-at least by those influenced by the individualist tradition. I want to suggest that we should view this incomparability as an expression of our profound separation, as an

${ }^{21}$ George Orwell, 'A Hanging' in Collected Essays (London: Secker and Warburg, 1961) p. 11. 


\section{Geoffrey Cupit}

expression of our status as individuals. And further, I want to suggest that we should understand the claim that we are to be treated as equals as following from the claim that we are to be treated as incomparable.

But, we may wonder, how can this be? How can treating people as equal be a way of treating them as incomparable? For surely, the obvious objection runs, to say that people are equal is indeed to compare them. How can treating as equal be a way of treating as incomparable? But there is a reply to such an objection. We may agree that we cannot say that people are both equal and incomparable. But we are not considering the argument that people are to be treated as equal because they are equal. We need not, then, claim that people are equal.

Nevertheless, we still need to explain the requirement to treat as equal. Why should treating as equal be a way of treating as incomparable; and why should this particular way of treating as incomparable (if that is indeed what it is) be chosen? The explanation, perhaps, is this: the point of treating people as equal is to act as a partial denial of-and thus to serve to qualify-the other comparisons we make and express. We say, rightly, that people are unequal-we say, rightly, that Mandela is superior to Hitler. Notwithstanding any inclination to view individuals as incomparable, justice requires no less. But (so the argument goes) justice requires that we treat each individual as a separate world. Given that justice requires that we make and express comparisons, we can hardly express our incomparability directly, that is, by eschewing the making and expression of comparisons. And thus we are forced to express our incomparability indirectly: we have no choice but to treat people as both unequal and equal, and by this equivocation to express their incomparability. In summary: we recognize that people are unequal, and must be treated as such; but we must also treat people as equals, not because they are equal, but in order to qualify the comparative judgments we express, and thereby treat each individual as a separate world. ${ }^{22}$

${ }^{22}$ If an argument of this kind is indeed the basis for the egalitarian position then that position is to be seen as, in an important sense, a negative one-though it is not the simple negative position noted at the outset. The point at which it negates is more fundamental, though the conclusion it reaches is more positive. The present argument goes beyond simply denying that certain sorts of bases (sex, race, birth, and so on) are relevant to an appraisal of us; it denies-albeit in a partial and equivocating fashionthe very practice of comparative appraisal. But the conclusion-the claim that justice does indeed require that (at least sometimes) we be treated as equals-is more positive than the mere rejection of certain bases for unequal treatment. 
As we have noted, a premise of this argument is the claim that justice requires each individual be treated as a separate world. But why should we accept that claim? The assertion of our separateness has, of course, been a feature of much recent liberal philosophy. In arguing against utilitarianism and for the inviolability of each person, Rawls and Nozick famously appealed to this idea, claiming that our separation must be taken seriously and respected. ${ }^{23}$ But even if we accept that we are separate and distinct (in some relevant sense) it still needs to be explained why this separation is morally significant. Even if we are separate, why is it wrong-indeed, why is it unjust-to treat us as if we are not? ${ }^{24}$

The problem here is this. To treat people as other than they are is sometimes unjust. People who are generous should not be treated as mean; people who are brave should not be treated as cowards. Such treatment is unjust because it is derogatory. But not all treatment of people as other than they are is derogatory. It is-or so we usually suppose-not derogatory (and therefore not unjust) to treat blue-eyed people as brown-eyed, or vice versa.

Why is it unjust to treat a generous person as mean, but not unjust to treat a blue-eyed person as brown-eyed? The difference, it seems, is that our generosity and bravery are relevant to an assessment or evaluation of us, whereas our eye colour is not. Generosity and bravery are virtues-we are superior if we have them. Eye colour does not-or, at least, should not-affect our standing, our status. As a consequence, treating blue-eyed people as brown-eyed is not derogatory.

We can now see the problem faced by anyone who wants to claim that justice requires that we take seriously the separation between people. Separateness seems too much like eye colour, and not enough like a virtue. Our separateness seems not to be relevant to an evaluation of us; it is not easy to see why we should suppose that

${ }_{23}$ 'Utilitarianism does not take seriously the distinction between persons' (John Rawls, $A$ Theory of Fustice, p. 27); and 'There are only individual people, different individual people, with their own individual lives. Using one of these people for the benefit of others, uses him and benefits the others. Nothing more. ... To use a person in this way does not sufficiently respect and take account of the fact that he is a separate person, and his is the only life he has. He does not get some overbalancing good from his sacrifice, ...' (Robert Nozick, Anarchy, State and Utopia, (Oxford: Basil Blackwell, 1974) p. 33).

${ }^{24} \mathrm{Cf}$. 'Although [Rawls] seems firm in his view that to each individual human being there corresponds exactly one 'system of desires', he never says why this must be so, or what exactly a 'system of desires' consists in, or why it is wrong to conflate them' (Michael Sandel, Liberalism and the Limits of Fustice, p. 167, emphasis added). 


\section{Geoffrey Cupit}

mere separateness makes a being superior, gives it a higher status than it would otherwise have. On the face of it, treating a separate being as not separate is not derogatory. Why, then, should we suppose such treatment unjust?

There are a number of possible responses to this problem. We might try to argue that our separateness does indeed make us superior, or that treatment can be unjust without being derogatory. ${ }^{25} \mathrm{I}$ shall not examine those lines of argument here. My inclination is to try to explain the injustice of failing to treat a separate being as separate, by invoking the notion of completeness.

The view that we are each a complete whole-that we are not, contrary to the myth related by Aristophanes, each of us 'the mere broken tally of a man'26 - is an important component, arguably even the central claim, of individualism. According to Anthony Arblaster, it is a view which arises at a particular historical juncture: 'Until the later medieval period it was usual to see human beings as incorporated in the natural and supernatural worlds. ... Wholeness and completeness belonged to the community, the polis, not to the separate human being ...'. ${ }^{27}$

What does it mean to say that we are each whole and complete in this context? It is not to say that we are in every sense complete. It is not to deny, for example, that we may develop some aspects of ourselves to the exclusion of others, that we may be one-sided-not rounded-individuals. Nor is it to deny that there are many ways in which we are dependent upon others. The relevant sense of wholeness here does, it seems, require that we are able to give a significant description of ourselves which does not require reference to that which is other than ourselves. But it must also, surely, be one that allows for a synthesis with membership. It must be possible for us to be complete in the sense required, and still a constituent member of a social union. What is excluded is the possibility that we are, or

${ }^{25}$ Feinberg claims that false judgments can be unjust without being derogatory: 'A false judgment or belief about a person is unfair to that person if either it is truly derogatory of him or else it severely misrepresents him in a way which is fundamental to his own conception of himself'

$\rightarrow$ 'Joel Feinberg, 'Noncomparative Justice', The Philosophical Review 83 (1974) p. 337). But whatever the merits of widening unfair judgments beyond the derogatory to include fundamental misrepresentation, it seems that such widening will not satisfactorily explain the (alleged) injustice of treating the separate as non-separate-for, I take it, even those who (mistakenly) believe themselves not to be separate are treated unjustly if they are not treated as separate.

${ }^{26}$ Plato, The Symposium, (Harmondsworth: Penguin, 1951), p. 62.

27 Anthony Arblaster, The Rise and Decline of Western Liberalism (Oxford: Basil Blackwell, 1984) p. 22. 
might become, mere parts of a society or tribe, mere bits of some greater social union, mere members of the human race, mere fragments of the universe. (There is, then, no reason to suppose that an attempt to base egalitarianism on individualism can appeal only to liberals, and that socialists must look for a different ground. Socialists may avail themselves of an individualist under-pinning of equality providing only that socialism is taken to require a synthesising of (rather than, at best, a trade-off between) the values associated with individualism and community.)

Suppose that each individual is indeed complete-in whatever the requisite sense of completeness is here. How does this explain the injustice of failing to treat individuals as separate beings? There are two points to be made. First, completeness, unlike separateness, does seem relevant to assessment and evaluation. So, at least, it is generally supposed. We suppose that being whole gives a being a certain status over that which is a mere part. Why this should be so is beyond the scope of this paper; but it seems plausible to suppose that at least part of the explanation invokes the idea that what is whole has, in some important sense, an independence, and that to be independent is to avoid a certain kind of fragility. Second, it seems that there is a relationship between completeness and separateness such that, in order to treat a being as complete it is necessary, in general at least, to treat that being as separate. Why should this be so? What is the relationship between completeness and separateness?

Separation does not imply completeness. There seems no reason to suppose that what exists in isolation need be anything more than an incomplete fragment. Similarly completeness seems not to imply separation. There seems no reason why what is complete may not be inextricably bound up with that which is other. Nevertheless, there seems to be a significant connection between the two notions, albeit not one of strict implication. There seems to be an expectation that-unless we have reason to think the contrary-what is separate from a thing is not required by that thing for its completion; and an expectation that-again unless we have reason to think the contrary-what a thing is not separate from is required by that thing for its completion. Given that this is so, it seems reasonable to say that, at least normally, to treat a being as complete it is necessary to treat it as separate.

My suggestion, then, is this: if we can show that each one of us is (in a relevant sense) complete, and if we can show that, ceteris paribus, a being which is complete is superior to one which is not, then we will have shown that it is unjust to fail to treat us as complete. We will then have an explanation of why-if the arguments I have sketched are sound-it is unjust to fail to treat us as separate, 


\section{Geoffrey Cupit}

and thereby an explanation of why justice requires that people be treated as equals. And, since this argument does not require us to hold that people are equal, we may endorse the egalitarian position without being embarrassed by our inability to explain on what such equality is supposed to be based, or how such equality is not undermined by our manifest inequalities. Our inability to justify the claim that all people are equal does not preclude our giving a rational justification for the claim that justice requires that all people be treated as equals-with whatever this implies. Of course I have not argued that we are complete, or, at any length, that completeness does confer superiority-and these claims certainly do require argument. ${ }^{28}$ But they are not, I suggest, so implausible as to make

${ }^{28}$ One reason why we should require argument for the claim that we are complete is that it is just not obvious. Another stems from the fact that there is reason to think that the belief that we are complete is, in the modern world at least, a comforting one. And if it is comforting then perhaps we should not be surprised if the belief is widely held, even if it is false. Why should the belief be thought comforting? If Arblaster is right, the view that individuals are complete arrives at a time (amongst much else, of course) of expanding horizons, and perhaps there is a connection here. While we have only a local knowledge and local associations, a belief in the significance of our own particular lives may sometimes be strained, but we may seem in no great danger of having our existences rendered utterly absurd. But as our understanding of what we are a part of grows, and as we discover the staggering enormity of what we are a part of - the age and size of the universewe can hardly fail to be overwhelmed by the utter triviality of our own existences. Perhaps we ought to respond by accepting that we (ourselves and others) are indeed but trivial fleeting associations of a few of the atoms that make up the vast cosmos-utterly infinitesimal, utterly insignificant. But if this is profoundly disquieting - as indeed it is - we might be tempted to try to deal with our awe at 'the starry firmament above' by looking within, and by asserting that there $i$ a world which begins and ends with each of us. The assertion of our own completeness is, we might say, one way to keep at bay the fate of being swallowed by a whole so large as to mock all our pretensions to significance, and more besides. ('To be sure, there may be no reason in principle why we cannot see ourselves as less than worlds, less than complete, but as significant parts of worlds less than the cosmos. But it does seem that once we see ourselves as less than complete, we take a step down a slope to insignificance. If we cannot hold the line at the boundaries of our own consciousness, there may seem still less hope-in the modern world at least-of finding a defensible boundary further out.) It seems possible, then, to offer a psychological explanation of why we might incline to a belief that we are each a complete world: when we do not have the sense to avert our gaze from the enormity of what surrounds us, conceiving of ourselves as complete may provide a vestige of comfort. If this is so, and if we wish to endorse only beliefs which are true, we should insist on an argument for the claim that we are complete. 
The Basis of Equality

an argument for equal treatment, grounded on our status as individuals, unworthy of serious consideration. ${ }^{29}$

University of Waikato

${ }^{29}$ For helpful comments and discussion I am particularly grateful to Sarah Bachelard, Kati Farkas, Jim Flynn, Bob Hale, Winifred Lamb, David Lumsden, Peter Morriss, David Neilson, Philip Percival, John Skorupski, Jack Vowles, and Robert Young. Versions of the paper were read at the AAP Conference (at Macquarie), the AAP (NZ) Conference (at Waikato), and the Atlantic Region Philosophers' Association Conference (at St Francis Xavier); at University College, Galway; and at the Universities of Glasgow, Hong Kong, Liverpool, St Andrews, and Waikato. I should like to thank all who participated on those occasions. I worked on this paper while holding a Visiting Research Fellowship in the Centre for Philosophy and Public Affairs at the University of St Andrews. 